\title{
MIDIATIZAÇÃO DA IMAGEM DE MULHERES NEGRAS COMO PROTAGONISTAS: EXPERIÊNCIA DE INTERAÇÃO DE BRASILEIRAS COM PUbLICIDADES CONTRAINTUITIVAS
}

\author{
Mediatization of the image of African-American women as protagonists: \\ Experience of Interaction of Brazilian women with Contraintuitive Advertisements
}

\author{
Francisco Leite \\ fcoleite@usp.br \\ USP-Universidade de São Paulo - Brasil
}

Recibido: 21-02-2017

Aceptado: 02-05-2017

\section{Resumo:}

Este artigo apresenta uma proposta de explicação sobre os nexos de sentido que são produzidos quando da interação de mulheres brasileiras com narrativas publicitárias contraintuitivas que apresentam mulheres negras como protagonistas de seus discursos. É uma investigação qualitativa orientada pela interligação teórica das perspectivas do Interacionismo Simbólico e dos Estudos da Midiatização, com foco nas influências da mídia na (re)elaboração das identidades sociais e no combate ao racismo, enquanto referencial teórico basilar e pela Grounded Theory Construtivista, como abordagem metodológica. O resultado desta pesquisa possibilitou a articulação do modelo teórico representativo "Experiências de interação de mulheres brasileiras com anúncios contraintuitivos" do qual neste artigo apresenta-se a categoria "A imagem da mulher negra em criações complexas e de representações extremas".

Palavras-chave: Publicidade contraintuitiva, Grounded Theory, midiatização, racismo, mulheres brasileiras.

\begin{abstract}
:
This paper presents an explanation proposal about the meaning links that are produced when there is interaction of Brazilian women with counterintuitive advertisements, which show AfroAmerican women as protagonists of their discourses. It is a qualitative investigation oriented by the theoretical interconnection of perspectives of Symbolic Interactionism and Mediatization Studies focused on influences of the media in the (re)elaboration of social identities, as basilar theoretical referential, and through the Constructivist Grounded Theory, as a methodological approach. The results of this research enabled the articulation of the representative theoretical model "Interaction experiences of brazilian women with counterintuitive advertisements", from which this paper presents the category "The image of the Afro-American woman in complex creations and extreme representations".
\end{abstract}

Keywords: Counterintuitive advertisements, Grounded Theory, mediatization, racism, brazilian women. 


\section{Introdução}

Este trabalho enquadra-se como uma relevante e necessária proposta de continuidade e avanço dos estudos sobre as repercussões de sentido do estímulo contraintuitivo na comunicação publicitária brasileira $^{1}$ (Leite, 2009, 2014; Leite e Batista, 2008 e Fry, 2002; entre outros). As articulações produzidas pela sua execução contribuem com os estudos dos Meios e da Produção Mediática que abordam a publicidade como objeto, visto que a originalidade desta investigação pauta-se pela construção de uma teoria substantiva sobre as experiências de interação de mulheres brasileiras (brancas e negras) com publicidades contraintuitivas, compreendendo pelos seus

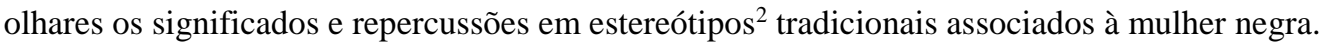

Com outras palavras, os resultados compartilhados neste artigo apresentam um recorte da investigação de doutorado do autor ${ }^{3}$ desenvolvida na Escola de Comunicações e Artes da Universidade de São Paulo, Brasil, sobre os nexos de sentido que são produzidos quando da interação de mulheres brasileiras com narrativas publicitárias contraintuitivas que midiatizam e oferecem visibilidade como protagonistas a mulheres negras.

A reflexão que estimula a construção do saber desta pesquisa é compreender como a publicidade - com suas inovações discursivas, como a estratégia contraintuitiva - pode, por meio do consumo e uso de suas estruturas narrativas, repercutir e contribuir socialmente ou não para o estabelecimento de (re)orientações sociais e cognitivas em prol de indivíduos alvo de estereótipos negativos.

Dessa forma, é na busca de organizar e ofertar esse saber que esta investigação inicia o seu trabalho empírico, enfrentando a seguinte problematização aberta e gerativa:

- Como a publicidade contraintuitiva, com a presença de mulheres negras, repercute nas estruturas de conhecimento e experiências da mulher brasileira?

- Quais efeitos de sentido (significados) são produzidos pelas lógicas de interação da mulher com o dispositivo publicitário contraintuitivo nos espaços e práticas da recepção?

\footnotetext{
${ }^{1} \mathrm{O}$ anúncio contraintuitivo (Leite, 2009, 2014) pode ser considerado como uma proposta do campo profissional publicitário que, estrategicamente, faz uso em suas narrativas de "outros/novos" conteúdos acerca de estereótipos dirigidos às minorias sociais ${ }^{1}$, isto é, de "moderadores contraestereótipos" (Blair e Benaji, 1996; Blair e Lenton, 2001; Dasgupta e Greenwald, 2001), com o objetivo principal de inovar e promover as suas tentativas de apelo para o consumo mercadológico, "violando expectativas intuitivas" (Upal, 2007; Boyer, 2001) dos receptores acerca dos discursos tradicionalmente veiculados pela publicidade. ${ }^{2} \mathrm{O}$ entendimento de estereótipo utilizado neste trabalho advém dos contemporâneos estudos da psicologia social que o compreende "[...] como crença coletivamente compartilhada acerca de algum atributo, característica ou traço psicológico, moral ou físico atribuído extensivamente a um agrupamento humano, formado mediante um ou mais critérios [...]”. (Krüger, 2004: 36-37).

3 Disponível em: http://www.teses.usp.br/teses/disponiveis/27/27153/tde-01062015-154355/pt-br.php [20/02/2017].
} 


\section{Referencial teórico}

O interacionismo simbólico (Mead, 1934/1982; Blumer, 1980) e o aporte dos estudos da midiatização (recepção, interação, mediações), com foco nas influências da mídia na (re)elaboração das identidades (Martín-Barbero, 1987; Braga, 2015, 2012, 2006; Hepp, 2014; Heep e Krotz, 2014 entre outros) são as perspectivas teóricas que orientam as reflexões e sustentaram a edificação desta pesquisa. Para situar o leitor/ a leitora, a seguir, é apresentado um breve panorama sobre os aspectos centrais desse quadro teórico, considerando o limite do espaço deste artigo.

Apesar de não apresentar um aporte teórico que responda todos os desafios impostos pela comunicação no contemporâneo, de acordo com Vera França, o interacionismo simbólico é uma frutífera perspectiva, que disponibiliza uma contribuição teórica insubstituível para apropriadamente se "pensar o processo comunicativo, a dinâmica relacional, a configuração das interações" (França, 2008: 90), sendo uma relevante corrente para apoiar o avanço dos estudos de recepção e as discussões do campo sobre os reflexos da midiatização nas mediações sociais.

A tradição do interacionismo simbólico indica que é no proceder da mútua afetação que os significados se estabelecem, produzindo sentidos pela interação dos indivíduos consigo e com os outros. Isto é, o seu realizar é operado quando os indivíduos relacionam-se buscando abstrair e interpretar as mensagens que produzem e recebem frente ao outro e que podem modificar ou não contextos e esquemas sociais mediante a reflexividade deste processo. Tal dinâmica articula-se concomitantemente também pela recepção de mensagens e pela produção de respostas de sentido a estas.

Observa-se nessa atividade, "a extrema importância da comunicação no pensamento de Mead; ela é inseparável do ato social que ajuda a realizar. Como componente do ato, a comunicação intervém na construção [da mente], do self e da sociedade" (França, 2007: 104), tendo em vista que é pela interação social, a comunicação entre indivíduos e a comunicação do indivíduo consigo próprio ${ }^{5}$, que as estruturas e os repertórios de significados desses objetos são edificados e promovidos em escalas de efeitos de sentidos.

"No entanto, França ainda enfatiza que "nem toda interação, como apontado anteriormente, é comunicativa. [...]. As interações comunicativas [...] se utilizam de gestos significativos. É a presença da significação, da linguagem, que delimita nosso terreno - embora os limites entre os dois campos sejam tênues" (França, 2007: 8).

\footnotetext{
${ }^{4}$ Grifo do autor.

${ }^{5}$ Essa dinâmica remete-se ao processo de intracomunicação "que ocorre internamente, em uma só pessoa" (Hohlfeldt, 2001: 61-62), em outras palavras, "temos um diálogo interior análogo a conversas que temos com os outros; esse dialogo interior constitui o que chamamos de mente. A mente não se resume, portanto, ao cérebro ou ao córtex, mas constitui um processo por meio do qual nossos objetos e experiências, que pertencem a nosso próprio corpo, e as imagens, que fazem parte de nosso passado, tornam-se parte de nosso self" (Nunes, 2005: 58).
} 
É neste contexto que se pode manifestar um entendimento sobre a midiatização, seus discursos e o seu alcance nas mediações sociais, ou seja, é possível pensar em "interações comunicativas" e em "interações mediatizadas" (França, 2007: 9), sendo que a primeira seria o processo de interação direta entre os indivíduos e a segunda seria uma rede interpretativa e cooperativa que se forma na sociedade integrando entre outros objetos o mercado, os profissionais de comunicação e os indivíduos receptores, produzindo afetações mútuas entre eles pela midiatização de produtos midiáticos elaborados (por exemplo, publicidade, telenovela, notícias etc.) em torno de uma determinada temática, que também busca estimular interações comunicativas ao alcançar a interpretação do outro.

Logo, associar esse repertório teórico às reflexões sobre as ativações interativas que podem ser estimuladas, por exemplo, por anúncios contraintuitivos que midiatizam a imagem de mulheres negras brasileiras como protagonistas indica um caminho relevante para observar o jogo interacional exercitado pelos indivíduos para a revisão e deslocamento de conteúdos estereotípicos negativos tradicionais associados a essa minoria, indicando aqui a possibilidade da auto-interação, da auto-reflexividade, bem como os seus impactos e manifestações diretas em estimular respostas sociais positivas ou negativas mediante os mediabuilding, isto é, pelas "formas de aprender como desenvolver sua própria vida, em relação à sociedade, em um ambiente mediatizado" (Bauer, 2010: 2). Devem ser considerados nessa perspectiva os sentidos em construção não hierárquicos elaborados/desenvolvidos pelas competências midiáticas dos indivíduos mediante as experiências de interação e manejo dos símbolos presentes em narrativas da mídia.

"Isto significa que a comunicação está relacionada com o uso de símbolos, os quais nós seres humanos aprendemos em nosso processo de socialização e que são principalmente "arbitrários" no sentido de que eles são baseados em regras socioculturais. Interação significa ação inter-relacionada de seres humanos. Neste ponto, o termo comunicação se baseia no interacionismo simbólico, como é adaptado na pesquisa de comunicação e mídia (Krotz, 2008a). Comunicação, então, é constitutiva para a constituição humana da realidade; isso significa que "construímos" (porém não apenas) nossa realidade social mediante múltiplos processos comunicativos" (Hepp, 2012: 186).

Nessa direção compreensiva, o aporte teórico desta investigação também está articulado considerando os pressupostos da midiatização, que delibera sobre a compreensão de um horizonte de regulação social influenciado pelos discursos da mídia e suas negociações e construção de sentidos. Dessa maneira, ambas as perspectivas teóricas (interacionismo simbólico e midiatização) coadunam-se e se complementam para direcionar o enquadramento interpretativo que possibilite direcionar as reflexões edificadas neste trabalho. Ainda neste sentido Friedrich Krotz reforça que:

\footnotetext{
${ }^{6}$ Tradução nossa.
} 
"Se seguirmos Berger e Luckmann (1980) e também George Herbert Mead (1934), o interacionismo simbólico e as posições teóricas relacionadas, nós podemos assumir que a sociedade, a cultura e todas as outras entidades sociais e culturais são socialmente construídas pelos indivíduos. Assim, podemos concluir que a comunicação é a relevante conexão entre a mudança das mídias e as mudanças na cultura e na sociedade" (Krotz, 2014: 827).

No entanto, para Hepp e Hasebrink (2013), se fez necessário e urgente edificar um conceito de médio alcance que abarcasse com expressividade as nuanças dialógicas e as potencialidades de conjunção dessas perspectivas consonantes, isto é, que conseguisse fundamentar a ideia geral da midiatização na interação social e simbólica e que viabilizasse pesquisas científicas pautadas por essa direção.

Com isso, com base nas propostas de Norbert Elias (1978) sobre configurações ${ }^{8}$, eles sugerem o termo "configurações comunicativas" (Hepp e Hasebrink, 2013: 189) para abarcar a amplitude reverberada pela realização de enquadramentos contextuais produzidos pela midiatização nas mediações sociais.

De acordo com Andreas Hepp, o conceito de midiatização deve ser "usado para analisar a inter-relação (de longo prazo) entre a mudança da mídia e da comunicação, por um lado, e a mudança da cultura e da sociedade, por outro, de uma maneira crítica" (Hepp, 2014: 51 ${ }^{10}$ ). Logo, no seu olhar, a midiatização precisa ser pensada numa perspectiva mais abrangente e nesse sentido um caminho seria considerar as suas manifestações nos contextos de "mundos midiatizados" (Hepp, 2014; Hepp e Krotz, 2014). Esses que, inicialmente, devem ser entendidos como certos "pequenos mundos da vida" (Luckmann, 1970) ou "mundos sociais" (Shibutani, 1955; Strauss, 1978), que em sua forma presente dependem constitucionalmente de uma articulação pela comunicação midiática.

Os mundos midiatizados são o nível no qual a midiatização se torna concreta e pode ser analisada empiricamente. A análise de tais realidades parciais "como mundos midiatizados significa pesquisar empiricamente a maneira pela qual sua construção comunicativa é institucionalizada e reificada pelas várias mídias, assim como sua construção comunicativa resulta em uma mudança das próprias mídias" (Hepp, 2014: 53-54).

Nesta linha, a investigação acerca da midiatização "não corresponde, então, a explicar ocorrências singulares pela indicação das lógicas supostamente inexoráveis que se encontrariam em ação. Corresponde antes estudar as experiências sociais de produção de circuitos e de dispositivos interacionais [...]" (Braga, 2008: 50), tentando perceber, nessas imbricações, onde se

\footnotetext{
${ }^{7}$ Tradução nossa.

${ }^{8}$ De acordo com Hepp, foi Elias que cunhou o conceito de "configurações", que na sua perspectiva deve ser entendido como 'redes de indivíduos' (Elias, 1978: 15) que constituem uma entidade social maior através da interação recíproca - por meio, por exemplo, da participação em um jogo, ou numa dança. Essa entidade pode ser uma família, um grupo, um estado, ou sociedade: em todos esses casos, essas entidades sociais podem ser descritas como diferentes redes complexas de indivíduos" (Hepp, 2014: 55).

9 Tradução nossa.

${ }^{10}$ Grifo do autor.
} 
produzem os significados e sentidos, bem como estão ocorrendo às mediações comunicativas para a estruturação de uma sociedade que competentemente use e consuma a sua mídia.

Dessa forma, com o objetivo de construir uma teoria substantiva que alcançasse as experiências de interações de mulheres brasileiras, brancas e negras, com anúncios contraintuitivos em seus mundos midiatizados, que se definiu edificar o percurso desta investigação seguindo os procedimentos e técnicas da Grounded Theory.

\section{Metodologia}

A Grounded Theory, identificada neste trabalho, a partir desse ponto, também como GT, baseada em investigação sistemática, é uma abordagem metodológica de pesquisa alicerçada em dados, os quais devem ser construídos e revelados a partir de um forte processo dialógico entre pesquisador e pesquisados, buscando evocar as experiências vividas dos participantes da investigação. Essa metodologia tem como orientação o paradigma interpretativo, que reconhece que não existe uma realidade estabelecida, mas sim interpretações construídas socialmente sobre a realidade, que podem ser observadas pelas investigações sociais.

Neste aspecto, portanto, considerando a originalidade desta investigação para o campo das Ciências da Comunicação e o pouco conhecimento teórico e empírico acerca das repercussões de sentido operadas pelas narrativas publicitárias contraintuitivas no social, a metodologia qualitativa $G T$ se mostrou mais pertinente para responder tais proposições, pois ela é geralmente utilizada em estudos que objetivam

“[...] explorar áreas substanciais sobre as quais pouco se sabe ou sobre as quais sabe-se muito, para ganhar novos entendimentos (Stern, 1980). Além disso, [metodologias qualitativas] podem ser usadas para obter detalhes intrincados sobre fenômenos como sentimentos, processos de pensamento e emoções que são difíceis de extrair ou de descobrir por meio de [metodologias] de pesquisa mais convencionais" (Strauss e Corbin, 2008: 24).

Dito isso, a principal proposição e fruto desta orientação metodológica é a construção de teorias substantivas ${ }^{11}$ capazes de explorar e articular explicações, baseadas nas realidades em foco dos indivíduos, sobre determinados fenômenos socioculturais.

O trabalho de campo desta investigação foi realizado no período de agosto de 2013 a outubro de 2014, junto a mulheres negras e brancas, acima de 18 anos, de diferentes classes econômicas,

\footnotetext{
${ }^{11}$ Glaser e Strauss (1967: 32-33) pontuaram a existência de duas principais tipologias de teorias: as formais e as substantivas. As primeiras são compostas pelo que eles denominam de grandes teorias, vistas como formais e abrangentes, enquanto o segundo tipo se refere às explicações para situações cotidianas, "que explicariam melhor as áreas específicas da pesquisa empírica já que essas teorias nasceriam diretamente de dados do mundo real" (Hutchinson, 1988 citado en Bianchi e Ikeda, 2008: 233).
} 
na região da Grande São Paulo, Brasil. Elas colaboraram fornecendo dados relevantes à pesquisa, que indicavam "opiniões, sentimentos, intenções [...], bem como os contextos e as estruturas de suas vidas" (Charmaz, 2009: 30).

De início, para a organização do corpus da pesquisa, ou seja, para começar a construção da amostragem teórica ${ }^{12}$, foram localizadas duas primeiras informantes, uma branca e uma negra, por indicação de mediadores, indivíduos terceiros, conhecidos e próximos do pesquisador. Posteriormente, a ampliação do corpus foi realizada mediante a aplicação da técnica snowball. Esta técnica permite ao pesquisador solicitar às suas entrevistadas indicações de próximas participantes potenciais para a pesquisa e "assim, sucessivamente, até que [seja] alcançado o objetivo proposto (o 'ponto de saturação')” (Baldin e Munhoz, 2011: 332) da pesquisa.

Em conformidade com os procedimentos da $G T$, o número de entrevistadas não foi estabelecido a priori, pois como informado a amostragem desta investigação atendeu a perspectiva da amostragem teórica.

Assim, foram entrevistadas vinte e quatro mulheres (entre dezenove e sessenta anos), sendo que três delas foram convidadas para novas entrevistas com o objetivo de aprofundamento de temas emergidos. Dessa maneira, a pesquisa agregou vinte e sete entrevistas sendo as informantes quinze mulheres que se autodeclararam negras e doze que se autodeclararam brancas. A definição pelos perfis das informantes justifica-se pela tentativa de alcançar um potencial comparativo que fornecesse um aporte sobre as experiencias de interação com as narrativas publicitárias contraintuitivas tanto pelo olhar de mulheres brancas quanto pelo olhar de mulheres negras.

Os nomes das informantes foram preservados, garantindo assim a confidencialidade. Elas estão identificadas ao longo deste texto pelas iniciais de seus nomes e sobrenomes.

Para a produção dos dados foi utilizada principalmente a técnica de entrevista em profundidade apoiada pela técnica de observação ${ }^{13}$. As observações foram registradas no caderno de campo do pesquisador e foram materiais ricos para a produção de memorandos sobre o processo de experiência do pesquisador com os conteúdos e reflexões produzidos nas entrevistas.

Após a leitura do Termo de Consentimento Livre e Esclarecido, a entrevista era iniciada, com questões gerais sobre o entendimento das informantes com relação à publicidade brasileira. Na sequência, para suportar a produção de dados junto à informante, eram apresentados os nove anúncios considerados contraintuitivos (figura 1). Essas peças foram escolhidas pelo autor, mediante uma pesquisa documental realizada na sua base de dados de anúncios contraintuitivos

\footnotetext{
${ }^{12}$ Em pesquisas de $G T$ observam-se dois vieses de amostragem que se complementam: a amostra inicial, que delibera sobre a participação e o perfil de indivíduos e locais, os quais subsidiarão o início da pesquisa; e a amostra teórica, que orienta os caminhos conceituais a serem explorados até a conquista suficiente de dados que apoiem a explicação de suas categorias [...] (Charmaz, 2009: 158).

${ }^{13}$ De acordo com Tarozzi, a peculiaridade da observação dentro da $G T$ "é que esta é focalizada imediatamente na observação dos fenômenos e, sobretudo, dos elementos de processo definidos na pergunta da pesquisa, dando menor peso à descrição do contexto" (Tarozzi, 2013: 111). Logo, a proposta da observação não se pauta por realizar descrições detalhadas, mas é focada na produção de conceituações do processo em investigação.
} 
organizada desde $2004^{14}$.

O critério para a escolha dos anúncios foi a visibilidade que suas narrativas davam à mulher negra em contextos de protagonismo qualificados de representação de trabalho, educação, finanças, realização/conquistas e sucesso profissional. Esse critério contextual pautou-se fortemente pelos dados da Pesquisa das Características Étnico-raciais da População (Osorio, 2013), realizada em 2008, que revelou ser a vida dos indivíduos influenciada por sua cor ou raça, sendo que tal influência era observada principalmente nas dimensões do trabalho, convívio social, espaço escolar etc.

Figura 1. Conjunto de nove anúncios utilizados nas entrevistas
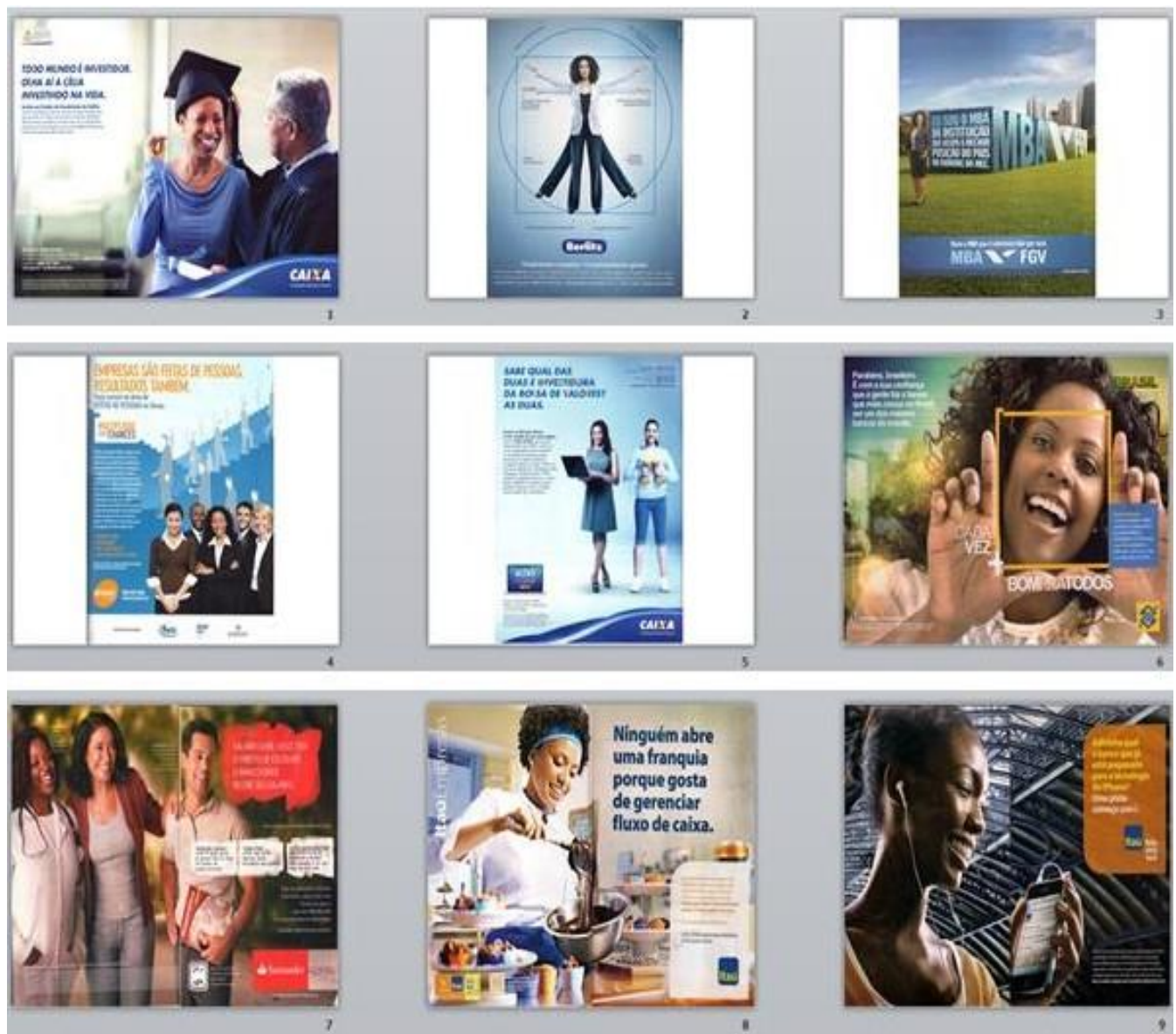

Fontes: (respectivamente) Revistas Istoé (2013), Exame (2011), Istoé (2012), Exame (2010), Exame (2011), Veja (2013), Veja (2013), Época Negócios (2012) e Rolling Stones Brasil (2008)

Considerando essa direção, os anúncios foram extraídos da mídia impressa (especificamente

${ }^{14}$ Os anúncios apresentam as características indicadas em Leite $(2009,2014)$. 
de revistas brasileiras) e não estavam necessariamente sendo veiculados nos "fluxos midiáticos" (Piedras, 2009) no período em que as entrevistas foram realizadas. Dessa forma, tais anúncios foram selecionados especialmente para se compreender os significados que podem ser produzidos quando do momento inicial de interação das mulheres com as suas narrativas.

Portanto, observando essa lógica, o conceito de "ponto de contato" (Trindade, 2008; Di Nallo, 1999) se apresenta mais pertinente para se entender o contexto de interação produzido quando das entrevistas, visto que o entendimento desse termo aponta para uma situação específica de interação com uma mensagem midiática, ou seja, uma situação distinta de uso e consumo mediático do discurso publicitário.

Cabe ressaltar que o objetivo desta pesquisa não foi explorar as mediações institucionais dos meios de comunicação, mas sim considerar o potencial de suas narrativas. Desse modo, a escolha de anúncios impressos estabeleceu-se pela sua facilidade de manuseio, recuperação e a proximidade direta de contato que tais narrativas viabilizavam no momento da realização das entrevistas. No entanto, é pertinente também informar que um pré-teste fazendo uso de um anúncio audiovisual contraintuitivo foi realizado e que os resultados obtidos pelas leituras das entrevistadas revelaram-se semelhantes aos produzidos pelos anúncios impressos.

Retornando à dinâmica da entrevista, com a apresentação dos anúncios, o entrevistador solicitava à entrevistada que escolhesse livremente, conforme seu autodirecionamento e motivação, de início apenas um deles. Novamente, a entrevistada era livre para fazer a sua escolha conforme os seus critérios. Com a escolha feita, o diálogo sobre as motivações da escolha e a sua compreensão sobre o anúncio desdobrava-se. Após os comentários da mulher sobre o primeiro anúncio, era solicitado a ela que, também conforme os seus critérios, motivações e autodirecionamento, ordenasse os anúncios, inclusive o inicialmente escolhido, agora considerando a ordem numérica de um a nove. Essa ordem simplesmente refletia o número de anúncios selecionados para estimular as discussões da entrevista.

As mulheres eram também questionadas sobre as razões que as motivaram a fazer suas organizações e, posteriormente, considerando distintamente cada anúncio, a entrevista seguia fluidamente. Ressalta-se que, apesar da consideração distinta sobre a narrativa de cada anúncio, não foram estabelecidas regras que neutralizassem os comentários das entrevistadas sobre eles quando elas queriam fazer correlações concomitantes entre as narrativas dos anúncios.

A análise dos dados foi realizada conforme os procedimentos sistematizados de comparação constante da $G T$, considerando as etapas de (1) codificação inicial, que pauta-se pela construção de códigos abertos; (2) codificação focalizada, quando os códigos iniciais são agrupados em conformidade com suas consonâncias e dissonâncias conceituais, bem como é nessa fase que se originam as primeiras categorias da pesquisa; (3) codificação teórica, que tem a proposta de integrar as categorias construídas que explanam sobre o fenômeno investigado. Nesta etapa também se busca identificar e definir a core category que tenha o potencial de integrar todas as categorias elaboradas permitindo, dessa forma, o desenvolvimento de um quadro explanatório teórico fundamentado nos dados. 
Esse proceder comparativo iniciou-se, especialmente, com a transcrição verbatim do áudio gravado de cada entrevista. A análise dos dados e o processo de codificação também foram apoiados pelo uso do software de análises qualitativas Nvivo.

Nos próximos tópicos, devido aos limites de espaço deste artigo, são apresentados apenas alguns recortes dos resultados desta investigação que como produto final edificou o modelo teórico representativo "Experiências de interação de mulheres brasileiras com anúncios contraintuitivos". Dessa forma, neste trabalho compartilham-se as dimensões de sentidos que articulam a categoria "A imagem da mulher negra em criações complexas e de representações extremas".

Assim, para compreensão da estrutura dessa categoria o leitor deve considerar que o nome dela está redigido em letras maiúsculas, as subcategorias com letras minúsculas e grifadas com negrito enquanto os componentes das subcategorias estão destacados em itálico e sublinhados.

\section{Resultados e Discussão}

A categoria A IMAGEM DA MULHER NEGRA EM CRIAÇÕES COMPLEXAS E DE REPRESENTAÇÕES EXTREMAS representa o enquadramento interpretativo das mulheres sobre as implicações de significado do uso da imagem da mulher negra em determinadas abordagens criativas de aspectos complexos e extremos.

Esta categoria é integrada pelas subcategorias: Neutralidade Perceptiva da Imagem do Negro e suas Associações em Criações Complexas e Enfraquecimento do Estímulo Contraintuitivo em Extremos Representativos.

\section{Diagrama 1 - Categoria A imagem da Mulher Negra em Criações Complexas e de Representações Extremas}

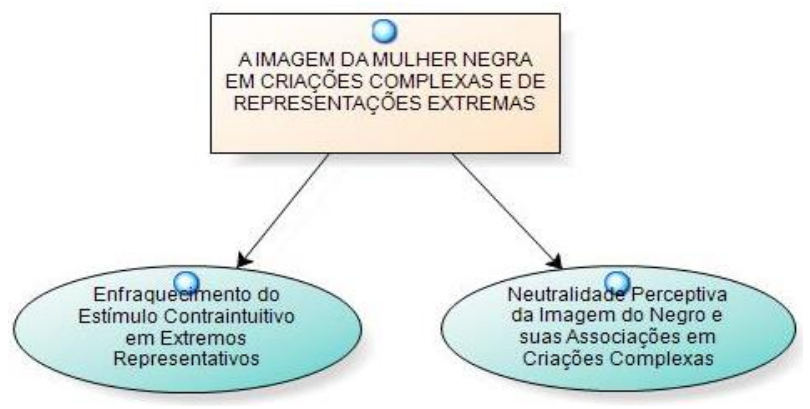

Fonte: Elaboração própria (Leite, 2015) 
As interpretações das mulheres contribuíram efetivamente para identificar um potencial enfraquecimento e fragilidade que o efeito contraintuitivo na publicidade pode ter quando apresenta em suas narrativas representações extremas acerca da imagem da mulher negra.

Nesse sentido, a subcategoria Enfraquecimento do Estímulo Contraintuitivo em Extremos Representativos, composta pelos componentes Representações de Extremidade Positiva e Representações de Extremidade Negativa, articula tais percepções das mulheres especificamente dirigidas a dois anúncios bem representativos utilizados na pesquisa: Itaú Franquia e Santander.

\section{Diagrama 2 - Subcategoria Enfraquecimento do Estímulo Contraintuitivo em Extremos Representativos}

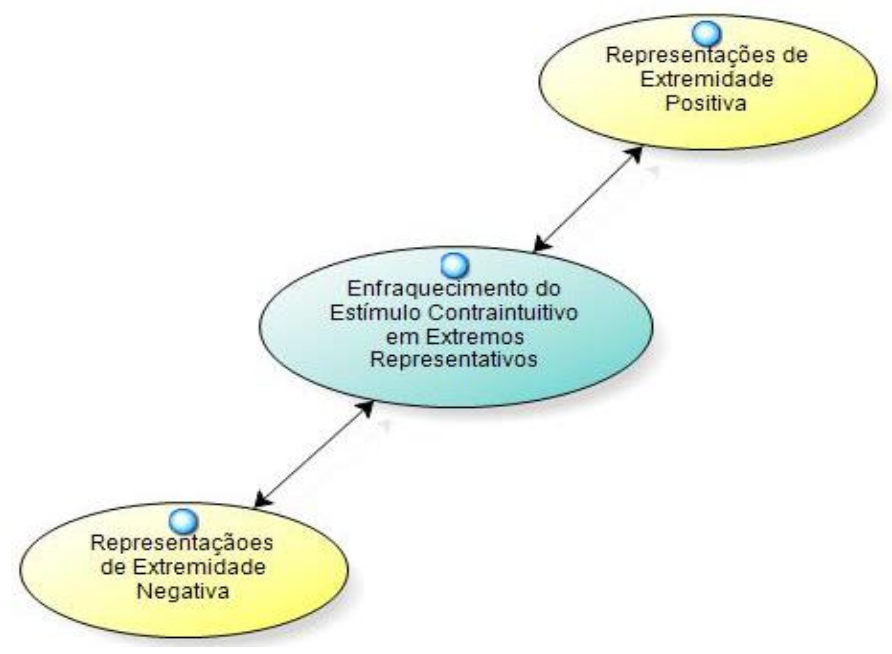

Fonte: Elaboração própria (Leite, 2015)

O anúncio do Itaú, considerando a perspectiva de extremidade negativa, na integração interpretativa de seus textos e imagens, traz a representação de uma mulher negra empresária de uma franquia de doces como protagonista. Porém, de acordo com as leituras das mulheres, a força das imagens deste anúncio posiciona, associa e direciona fortemente esta mulher não aos significados acerca do mundo dos negócios e das empresas, como se esperaria pela linha informativa do anúncio, mas aos tradicionais estereótipos promotores de preconceitos sociais que vinculam a imagem do negro à subalternidade, no referido caso, à cozinha e ao trabalho operacional de uma cozinheira. 


\section{Figura 2: Anúncio Itaú Empresas/Franquias}

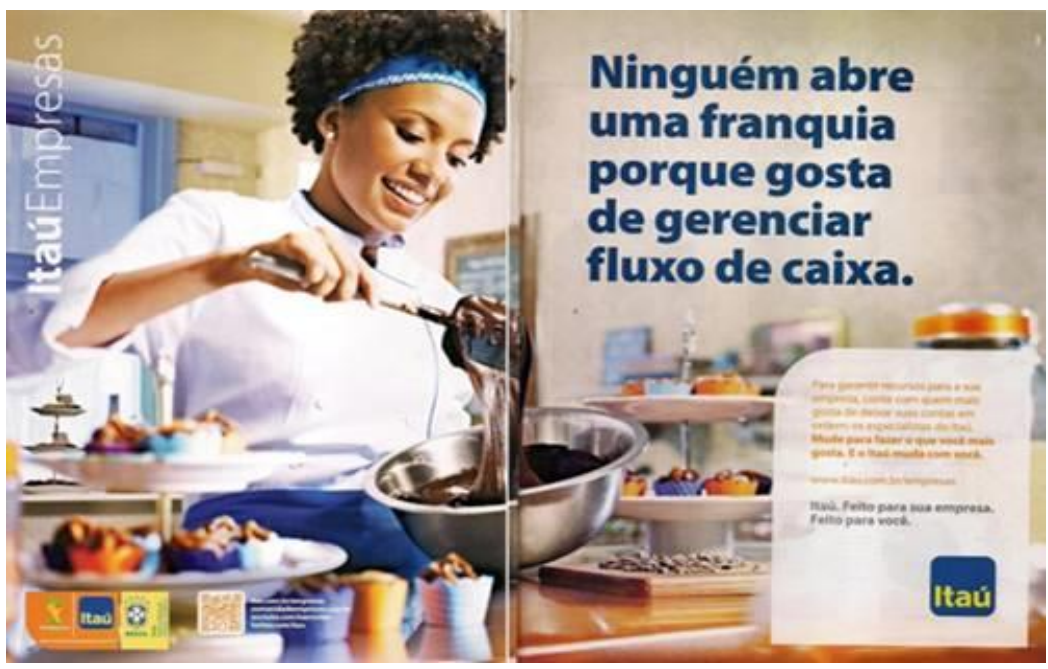

Fonte: Revista Época Negócios (2012)

Em outras palavras, no anúncio do Itaú Empresas a mulher negra no conjunto da mensagem é indicada como a proprietária de uma recente franquia gerenciada pelos profissionais do Itaú. No entanto, pelo contexto criativo da imagem na qual a mulher negra aparece, é possível de acordo com as informantes observar dois níveis de leitura, quando da interação com essa narrativa: o primeiro manifesta-se automaticamente associando a imagem da mulher à cozinha. Já o segundo, manifesta-se após a leitura completa do anúncio, isto é, depois que as entrevistadas compreendem o conjunto do anúncio lendo a imagem e o texto e constatam que a mulher seria na realidade a proprietária da franquia.

Com a compreensão geral do anúncio, a maioria das mulheres é enfática ao ressaltar que apesar do texto do anúncio informar que se trata da proprietária da franquia, a imagem dela na cozinha com uma panela não remete à imagem indicada de uma empresária, mas sim à de uma cozinheira, empregada da empresa. Algumas mulheres chegam a indicar a possibilidade de "preconceito velado" (Santos, 2006) no anúncio, que passaria uma imagem "subliminar" de que o negro avançou mas o lugar dele continuaria sendo na cozinha.

Nesta publicidade a mulher negra é protagonista, mas ela aparece como uma empregada. A negraé a dona da franquia, se você ler o texto. Mas na imagem, para mim ela é a empregada, a chefe da cozinha. Agora no texto está dizendo que ela é a dona, mas para mim é uma forma subliminar de dizer que a negra é uma empregada. [...]. Ela não poderia ter empregados para fazer isso? Por que ela está cozinhando? Por que logo ela tem que estar cozinhando? Por que sempre o negro está na cozinha ou fazendo faxina? Então, eu entendi que foi um preconceito. Eu entendi isso. Ela não tem empregado nenhum, ela está fazendo. Quer dizer, está fazendo referência a ela que é negra e como se ela não tivesse capacidade ou sei lá [...], algo do tipo. Mais eu senti um preconceito aqui porque ela é negra 
e ela está cozinhando. Normalmente é o negro que fica na cozinha. [...]. Por que não tem uma pessoa fazendo para ela? Por que ela não está com uma roupa social? Sei lá. Divulgando a empresa no site, com um computador na mão. Divulgando num blog e deveria ter outras pessoas fazendo essa mistura para ela. Por que ela está mexendo a massa do bolo? Só por que ela é negra e sabe cozinhar? É isso? [...]. Ela está na cozinha fazendo um trabalho que não era para ser dela. Se ela é a dona da franquia não tinha o porquê dela estar cozinhando (GLSS, Mulher Negra).

Eu vejo a mulher negra feliz, conquistando mais um degrau na vida. Ela me mostra ser uma pessoa muito positiva. Por outro lado, uma pessoa muito preconceituosa não iria nem prestar atenção na publicidade. Uma pessoa preconceituosa iria falar assim: "uma preta com uma faixa na cabeça, com os cabelos encaracolados, com uniforme: é uma empregada". Ele não iria achar que ela é uma empresária. Se fosse uma loira no lugar da negra a pessoa preconceituosa iria achar apenas que era uma empresária. Ela não vai achar que a negra é empresária num primeiro momento, só se ler o texto. Ai ele pode mudar a opinião, por que no texto deixa claro que ela é a empresária (JSCN, Mulher Negra).

Aqui o Itaú [...] uma negra cozinhando é "ninguém abre uma franquia para gerenciar fluxo de caixa" [lendo a redação do anúncio em voz alta]. É [pensando] uma negra, sei lá, mostrando seu dom e aproveitando a oportunidade do Itaú. $O$ dom da cozinha de cozinhar. Porque cozinha remete-se a... [silêncio] antigamente que a negra que cozinhava e seu dom, negra, mulher, cozinha. Associando seu dom de cozinhar com a oportunidade do Itaú de conseguir crédito. É uma negra que também conseguiu ter uma franquia com o seu dom, então qualquer outro [indivíduo] consegue (CEL, Mulher Branca).

Esta daqui é do peru. "Ninguém abre uma franquia porque gosta de gerenciar fluxo de caixa". [...]. Agora, isso daqui, você vai perguntar para mim o que isso tem a ver. Por que esta moça está justamente fazendo chocolate? Porque é uma delícia [risos]. Por que é que ela está batendo o chocolate? Por que ela não está na frente da loja dela já que é uma franquia? Por que ela tem que estar batendo chocolate? Quando o anúncio é do banco, é do investimento. Por que não colocaram essa moça diante da franquia dela sem precisar mexer no chocolate? Não sei, não passa o recado [silêncio] de uma franquia. Será por que ela não gosta de gerenciar fluxo de caixa? [...]. É uma moça negra que está aqui com uma panela batendo um chocolate. Lembra muito cozinha. Não lembra franquia. Isso daqui lembra uma negra, uma doméstica. Não lembra uma investidora. Não lembra uma mulher que investiu numa franquia para ter um bem dela. [...]. Para mim não dá. Ele [anúncio] não conseguiu me convencer. Não conseguiu me convencer. Mas, a tentativa foi olhe são todos iguais. Porém, a gente sabe muito bem Francisco. Vamos colocar os pés no chão! A gente hoje tem uma diminuição, mas o preconceito existe. A menina é linda, mas por que essa fotografia não foi feita com essa menina na frente da loja dela? Por que ela foi bater bolo? Por que não tem esses docinhos e ela ao lado dizendo que ninguém abre uma franquia porque gosta de gerenciar fluxo de caixa? Isso daqui lembra cozinha. Isso daqui lembra coisa serviçal. Se fosse uma branca provavelmente não lembraria. Mais é uma negra, então a imagem que vende é que ela está batendo alguma coisa que nem pertence a ela. [...]. Parece que ela trabalha para alguém, quando na realidade o banco quer vender que ela é uma empresária (NMA, Mulher Branca). 
Já o segundo anúncio do Santander exemplifica a perspectiva de extremidade positiva. De acordo com as interpretações das mulheres, o anúncio apresenta em seu contexto uma mulher negra como destaque, juntamente com mais dois indivíduos - uma mulher e um homem - ambos de cor branca. Na representação publicitária a imagem da mulher negra é automaticamente, numa primeira leitura, associada à imagem de uma médica para algumas mulheres e para outras a imagem de uma enfermeira. Essas leituras se estabelecem, segundo as mulheres, tendo em vista o uniforme branco que a mulher negra está vestindo e o estetoscópio localizado em volta do seu pescoço. Porém, com a realização de uma leitura mais atenciosa do anúncio é possível localizar uma legenda que identifica a mulher como enfermeira.

\section{Figura 3: Anúncio Santander}

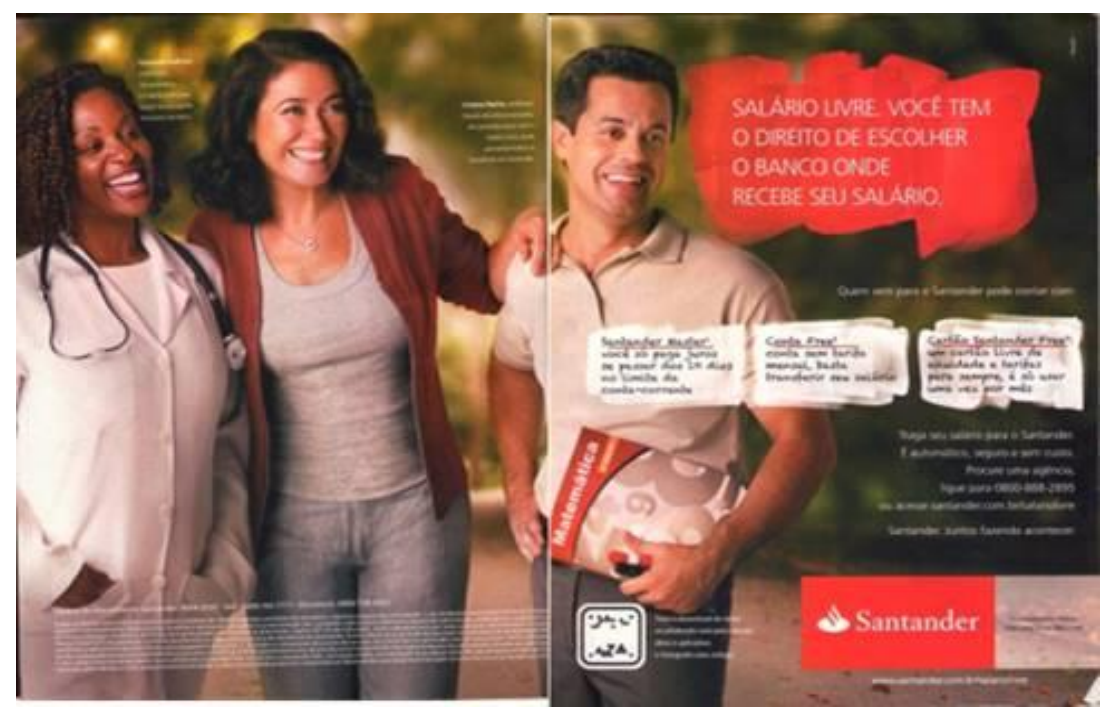

Fonte: Revista Veja (2013)

Esse anúncio, no olhar das mulheres, gera uma grande dissonância, primeiro porque é complexo definir numa primeira leitura se a mulher é médica ou enfermeira. Neste cenário, se observa como a imagem nos anúncios possui fundamental relevância, pois este seria o primeiro e, talvez, o mais forte estímulo das narrativas publicitárias. Os anúncios, pelo que se observou, começaram a ser interpretados pelas imagens, o que instantaneamente produziu essa dissonância interpretativa entre as mulheres.

Portanto, o uso da representação positiva de associar a mulher negra com o campo da saúde formou um grande desconforto e estranhamentos acerca do uso da imagem da mulher negra, pois apesar do anúncio posicionar a mulher negra como destaque de sua narrativa, para algumas mulheres a representação que dá margem para associar a mulher negra à uma médica não é condizente e nem convincente. Isso por que na realidade do dia-a-dia não existem muitas médicas e médicos negros, devido às limitações historicamente impostas a esses indivíduos, bem como 
aos altos custos de um curso universitário de Medicina no Brasil, que não se enquadraria nas possibilidades financeiras da maioria dos negros do país.

[...] Medicina é um curso caro. É um curso para quem já tem uma condição financeira bem melhor. Muitos preferem fazer um curso de auxiliar de enfermagem, levantar uma grana para poder fazer uma Medicina futuramente. Porque Medicina é um curso caro. Você vê muito mais negros na área da Enfermagem do que na área da Medicina (SA, Mulher Negra).

Na minha cabeça veio enfermeira não sei dizer o porquê (LS, Mulher Branca).

Esta daqui pela roupa eu falaria que seria uma enfermeira [neste momento a entrevistada mostra incerteza pelas suas expressões faciais]. [a entrevistada para e de repente de modo constrangido diz:] Engraçado, Francisco, eu não falaria que ela é médica e ela pode ser médica. Não falaria devido ao perfil. Olha que preconceito [a entrevistada mostra-se constrangida]. Pelo perfil de ser negro. É difícil uma negra fazer Medicina, meu! Vê os médicos por aí, é muito difícil você encontrar um médico negro. É muito difícil. Você pode, talvez, ir a vinte consultórios e você encontra um negro em vinte consultórios. Talvez, hein! Pois, eu acho que é bem maior, pelo custo do curso. Eu falaria, engraçado, eu falaria enfermeira não falaria médica. [...]. Não falaria que era médica. Falaria que ela é enfermeira. Porque minha experiência de vida, Francisco. Eu vou em médico para caramba, todo ano faço aquelas rotinas. Eu nunca encontrei um médico negro. Não tem, não tem. Não tem médico negro. Eu nunca fui consultada por um médico negro (LNL, Mulher Negra).

Enfermeira [...] está escrito. Se eu não lesse a publicidade automaticamente eu iria falar que ela é médica pelo jaleco e pelo estetoscópio que é bastante vinculado a médico automaticamente e não falaria que ela é enfermeira (TRA, Mulher Negra).

Uma médica, uma fisioterapeuta. Ah! Está dizendo que ela é enfermeira. Para mim ela poderia ser médica, mas colocaram enfermeira (HM, Mulher Branca).

Então, uma pode ser uma médica. Não, está aqui enfermeira. Vamos ler, não é? Quando eu bati o olho no jaleco e estetoscópio já pensei na área da saúde e já veio médica (LCSO, Mulher Branca).

No entanto, para outras mulheres apesar dessa realidade de poucos médicos negros na sociedade brasileira, o simples fato da publicidade fazer circular essa imagem já estimularia a autoestima de muitos negros, na situação de interação com anúncios como este do Santander. Porém, as informantes criticam o jogo que disfarçadamente identifica a negra na legenda como enfermeira. Em resumo, esta propriedade expressa e coaduna a percepção de que quando as mulheres interagem com anúncios que apresentam em suas narrativas extremos de representações associados aos estereótipos- a exemplo dos anúncios do banco Santander, que traz a imagem de uma mulher negra associada à área da Saúde (médica ou enfermeira), e a do banco Itaú, associando outra mulher negra a uma franquia de alimentos (empresária ou cozinheira) - tais representações acionam um processamento de informação que gera um considerável desconforto 
entre as receptoras entrevistadas. Pois muitas mulheres não leem o anúncio de modo completo e inferem automaticamente a mulher negra em papéis sociais, considerados pelo senso comum, como de menor prestígio.

Como exemplo, quando observaram a mulher negra no anúncio do Santander, o pensamento automático $^{15}$, considerando os estímulos do uniforme branco e estetoscópio, é associá-la a uma profissional da enfermagem. Em alguns poucos casos a mulher negra é associada a uma profissional médica. Porém, essa última indicação vem sempre acompanhada de incerteza e justificativas pautadas pela dificuldade social dos negros conseguirem cursar uma faculdade de Medicina, tendo em vista a alta concorrência nas universidades públicas e o alto custo dos cursos.

Enfim, com essas observações é possível sugerir que o efeito contraintuitivo enfraqueceria o seu impacto nos anúncios quando são utilizadas representações extremas positivas e negativas associadas aos estereótipos inscritos aos indivíduos estigmatizados. Desse modo, deve-se entender que o efeito contraintuitivo não se localizaria nos extremos representativos. Logo, o efeito de sentido contraintuitivo é produzido em outras vias distantes das abordagens que apelam para o uso de representações extremas como os exemplos de ambos os anúncios considerados.

Neste horizonte, as mulheres entrevistadas também revelaram pelas suas interpretações a possibilidade de neutralidade de tais manifestações em anúncios que apresentem a imagem da mulher negra sob o prisma de criações complexas. Esta perspectiva é apresentada na estrutura da subcategoria Neutralidade Perceptiva da Imagem do Negro e suas Associações em Criações Complexas. O entendimento desta subcategoria está pautado em dois componentes: Dificuldade de Compreensão do Anúncio e Criatividade Complexa Neutraliza Reflexões e Associações Estereotípicas.

\section{Diagrama 3 - Subcategoria Neutralidade Perceptiva da Imagem do Negro e suas Associações em Criações Complexas}

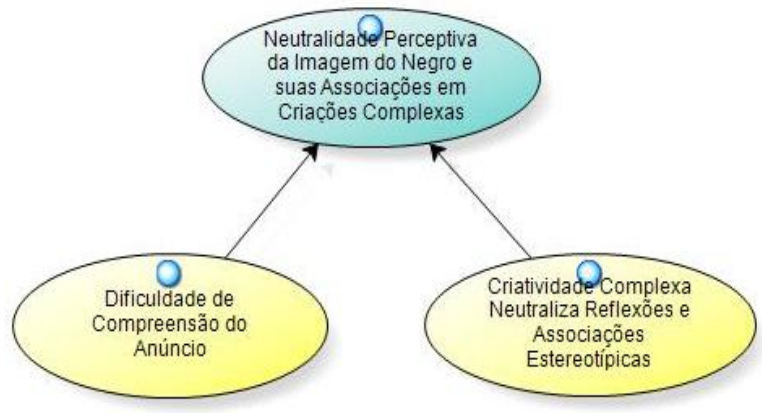

Fonte: Elaboração própria (Leite, 2015)

\footnotetext{
${ }^{15}$ Ver Leite (2014) e Bernardes (2003).
} 
Esta subcategoria emergiu pela interpretação e observação das mulheres diante da publicidade do anunciante Berlitz Corporation, conceituado instituto multinacional de cursos de idiomas e treinamentos especiais para formação de indivíduos/executivos globais. Nesse anúncio, uma mulher negra está vestida classicamente como uma profissional executiva. A estrutura criativa da peça faz uma analogia ao famoso desenho do "Homem Vitruviano" ${ }^{16}$, de Leonardo da Vinci. No entanto, é uma mulher negra que está no enquadramento do pentagrama, que nas suas extremidades, pontas e entornos destaca os serviços especializados oferecidos pelo Berlitz. Os serviços estão descritos em Inglês.

Ainda no rodapé deste anúncio, abaixo do logotipo do Berlitz, é possível ler o slogan "Totalmente completo. Completamente global", seguido da redação "Para ser um profissional que atende às expectativas de um mercado cada vez mais exigente e competitivo, saber outra língua é só o primeiro passo. Por isso, o Berlitz oferece de cursos de idiomas até treinamentos especiais para formação de pessoas globais”.

\section{Figura 4: Anúncio Berlitz}

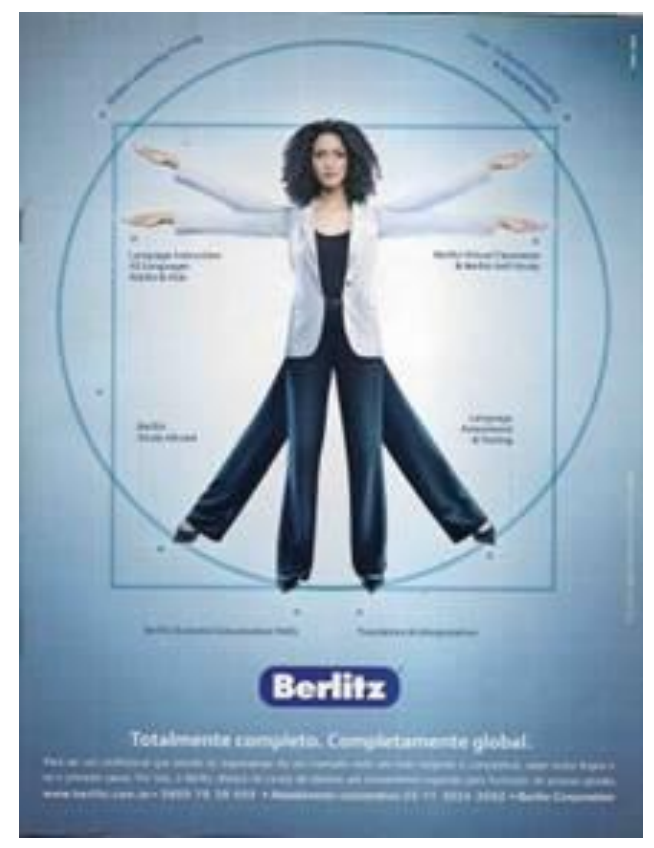

Fonte: Exame (2011)

\footnotetext{
16 Para saber mais sobre o desenho de Leonardo da Vinci acessar: http://discoverybrasil.uol.com.br/web/davinci/historia/Homem-Vitruviano/?cc=BR [16/10/2016].
} 
$\mathrm{Na}$ interação com essa narrativa, as informantes foram taxativas ao classificá-la como confusa e complexa, não sendo, portanto, possível compreendê-la adequadamente como as outras publicidades apresentadas. Em síntese, percebeu-se uma Dificuldade de Compreensão do Anúncio.

Nossa! Mais é tudo em Inglês. Ficaram mais destacados os cursos de línguas [...]. O que mostra aqui é que você tem que estudar, de fazer algum curso e se atualizar no mundo. Eu achei a mulher negra bem destacada no centro. [...]. As palavras em Inglês [...] eu não sei Inglês e fica difícil compreender a linguagem (JSCN, Mulher Negra).

Eu seria mais explicativa. As opções que dão aqui, já estão em Inglês todas as opções. Tem que se pensar que [...] a revista Exame, é mais segmentada, mas passa na mão de outras pessoas de níveis diferentes. Os nomes dos cursos estão em Inglês. Então eu acho que colocaria os nomes em Português ou os nomes em Inglês só que com uma pequena explicação do que é o curso. [...]. Então eu acho que ela deveria ser menos simbólica, utilizar menos símbolos [...] e colocar algo mais explicativo (TRA, Mulher Negra).

Eu não entendi a peça e não sei expressar o que eles pretenderam aqui. [...]. Sinceramente. Achei meio confusa. Não fica claro o que eles querem dizer. Tudo bem que eu não entendo desse tipo de linguagem [publicitária], mas todo mundo deveria compreender quando olha. Não é? Desde uma pessoa mais qualificada, até uma pessoa mais simples (IAM, Mulher Branca).

Está tudo misturado aqui. Fica difícil de entender. É algo ligado [silêncio] com cursos [silêncio]. Não me deixa nada. Não me passa nada até mesmo pelo layout dessa transformação dessa moça que pode ser duas ou três. Essa multiplicação. A própria narrativa embaixo, o texto que fala dos cursos que você precisa saber não só uma língua, treinamentos especiais, informações globais..., Mas não consigo ver isso como uma mensagem de alguma coisa não. Acho muito ilustrativa. Aliás, não tem preconceito nem nada. Está muito bonito, só não dá o recado. Ela está estática aqui. Para mim, não diz nada (NMA, Mulher Branca).

São nessas tentativas de produção de sentido para se compreender a narrativa, devido provavelmente à exigência de conhecimento de história da arte e de outro idioma, que essa Criatividade Complexa Neutraliza Reflexões e Associações Estereotípicas acerca da imagem da mulher negra como protagonista do anúncio. Este componente também pode ser considerado sob um aspecto de coalisão, ou seja, exigiria um processamento maior para a categorização, e assim a raça provavelmente não ganha destaque avaliativo.

Eu achei bem legal. Batendo o olho é bem interessante, mas eu não sei. Eu sei um pouco de Inglês. Eu vou precisar mais do Inglês, o que eu poderia entender do anúncio? Eu tento ler e não entendo. Então, o anúncio fala comigo justamente por essa razão de eu não entender o que ele oferece? É algo ao contrário? Então eu preciso mesmo do Inglês, pois se nem o anúncio eu entendi. Como eu vou conseguir trabalhar etc... Entendeu? É um apelo ao contrário (LCSO, Mulher Branca). 
Este dai eu não sei te falar porque para mim é confuso. Eu não sei nem falar Inglês e nem ler (VLFSG, Mulher Branca).

Eu não gostei da foto dessa mulher. Eu não gostei. Eu achei ridículo e muito nada a ver. Essa imagem dela como se fosse copiando aquela imagem o homem no centro de tudo. Eu não gostei da imagem dela com isso. E para mim, eu achei nada a ver porque eu não consigo enxergar nisso que ela está falando que são línguas. Entendeu? Eu só vi que era quando eu li aqui em baixo. [...]. Aqui ela está se mostrando uma mulher de muitas [silêncio]. Eu não gostei. Ele [anunciante] está tentando dizer aqui que ela é totalmente completa e global, mas eu não acredito que seja com essa imagem que eles estão mostrando aqui (AAS, Mulher Negra).

Com o exposto, a percepção das relações de sentido da publicidade como estrutura de vínculos e conexões complexas é compartilhada nos discursos das mulheres que a compreendem plenamente como um discurso multifacetado de origem mercadológica, com relevante expressividade, ou seja, como uma fonte de polarização de experiências mediadas, potencialmente (re)modeladoras dos selves dos indivíduos que interagem com o universo simbólico dos seus discursos.

Com a compreensão desta lógica, entre as experiências vividas e experiências mediadas das mulheres informantes desta pesquisa, o conhecimento produzido nesta pesquisa ganha relevo para ser discutido e considerado sob essas bases catárticas de articulação multifacetada. Nessa condução, pelos olhares das mulheres (brancas e negras), no que se refere ao uso de negros como protagonistas, as experiências de interação das informantes com os anúncios trouxeram à baila dois relevantes pontos que problematizam e orientam as repercussões de sentido da publicidade contraintuitiva.

Primeiramente, mediante os discursos das informantes, observou-se com nitidez uma provável ocorrência de neutralidade perceptiva da imagem da mulher negra e suas associações estereotípicas em criações complexas. Essa observação se estabeleceu fortemente na interação das mulheres com o anúncio do Berlitz.

A linha criativa desse anúncio sugere que o ciclo de significados associados aos estereótipos negativos atribuídos aos negros podem ser neutralizados, quando da presença de negros protagonistas em criações que tragam fortes elementos distratores perceptivos. Desse modo, tais elementos exigiriam dos receptores um esforço cognitivo maior para o entendimento do conjunto do anúncio, o que deslocaria o seu foco atencional para outras percepções. Nesta linha, provavelmente, essa dinâmica ocasionaria uma neutralização de associações (positivas ou negativas) às imagens dos negros.

Outro ponto revelado se expressa pela observação de que o efeito contraintuitivo não se localizaria em extremos representativos positivos ou negativos acerca de papéis sociais, pois a inclusão da presença de negros nesses espaços extremos de representação, como observado nos anúncios do Itaú Franquia, que associa uma mulher negra (in)diretamente ao campo 
empresarial de franquias, em um cenário que remete à cozinha (empresária x cozinheira); e o anúncio do Santander, que expõe a representação da mulher negra associada ao campo da Saúde (médica x enfermeira). Tais anúncios, ao articular suas narrativas nesses extremos representativos negativos e positivos, promoveram leituras atravessadas por polêmicas e incertezas sobre tais posições profissionais associadas à mulher negra.

Esses desvios interpretativos podem produzir efeitos adversos e indesejados como o efeito de ricochete (Wegner, 1994; Bernardes, 2003; Byrne e Hart, 2009). Enfim, o estímulo contraintuitivo para o deslocamento de conteúdos estereotípicos nesses enquadramentos seria enfraquecido ou até mesmo pode-se entender que o efeito contraintuitivo não se encontraria nessas extremidades, que apenas produzem conflitos cognitivos e não agregam diretamente novos elementos para o deslocamento de conteúdos estereotipados.

Nos meandros dessa elasticidade perceptiva promovida em torno da inclusão da presença de mulheres negras como protagonistas de discursos publicitários, é consenso entre as mulheres informantes, tantas brancas quanto negras, que elas estão testemunhando efetivamente um movimento de mudança mais articulado do campo publicitário em direção à inclusão de indivíduos negros em suas narrativas em contextos mais qualificados.

Nesse contexto, apesar das prováveis estratégias, desvios e possibilidades de efeitos adversos, são claros para as mulheres os movimentos reais, porém ainda não ideais, que estão sendo produzidos nos circuitos da midiatização no sentido de articular alternativas discursivas, como a publicidade contraintuitiva, para agregar "novas/outras" informações que possam contribuir para atualizar a percepção social acerca da imagem dos negros, movimentando significados nesse sentido em níveis individuais e coletivos.

Desse modo, diante dessa complexidade em torno dos usos e consumo da imagem dos negros na publicidade e na mídia, quais seriam os caminhos mais adequados para realizar abordagem de suas representações em discursos publicitários?

Pelos resultados obtidos neste estudo, sustenta-se a evidência que a proposta de simplesmente inserir os negros como protagonistas de anúncios, em contextos positivos de representação, como propõe a lógica da publicidade contraintuitiva, não seriam suficientes para operar de modo efetivo o deslocamento de conteúdos estereotípicos, tendo em vista os elementos velados, como já discutido, que pré-atencionalmente podem estar presentes em suas dimensões de sentido.

No entanto, a condição da proposta da "configuração midiática" (Hepp, 2014) contraintuitiva de movimentar a estrutura dos conteúdos de estereótipos negativos não é descartada pelas mulheres brasileiras, que acreditam que a proposta publicitária, contraintuitiva ou não, pode sim colaborar nesse sentido pelo seu impacto de "violar a expectativa intuitiva" (Upal, 2007, 2009) dos estereótipos tradicionais. No entanto, ela precisaria ser aprimorada. 


\section{Considerações finais}

Para os estudos acerca das repercussões da publicidade contraintuitiva (Leite, 2009; 2014; Leite e Batista, 2008 e Fry, 2002; entre outros), os resultados desta investigação representam um avanço e fornecem um amplo, consistente e fundamentado repertório de conhecimento empírico para esta contemporânea área de estudo. O conhecimento empírico que estrutura o modelo teórico construído do processo de EXPERIÊNCIAS DE INTERAÇÃO DE MULHERES BRASILEIRAS COM ANÚNCIOS CONTRAINTUITIVO, bem como o seu recorte apresentado neste artigo sobre a categoria A IMAGEM DA MULHER NEGRA EM CRIAÇÕES COMPLEXAS DE REPRESENTAÇÕES EXTREMAS, buscou explicitar as repercussões que anúncios contraintuitivos podem produzir na sociedade (considerando o aspecto individual e coletivo) pelas suas tentativas de deslocar conteúdos negativos de estereótipos atribuídos às minorias sociais como as negras e os negros brasileiros.

Este é esforço original dentre as poucas pesquisas desta área no Brasil e no mundo que, geralmente, apoiam-se em reflexões teóricas exploratórias. Portanto, o valor do saber produzido nesta investigação deve ser considerado como um relevante e inédito contributo, tendo em vista que não se tem registro na literatura sobre trabalhos que se proponham a organizar um quadro explicativo teórico sobre as lógicas de interação de mulheres brasileiras com dispositivos publicitários contraintuitivos, isto é, que foquem explorar o que acontece nos espaços de recepção quando mulheres interagem com tais narrativas, ainda mais pensando nesta situação as possibilidades de deslocamento de estereótipos negativos associados a grupos estigmatizados como os negros brasileiros, que enfrentam no seu cotidiano as expressões do racismo.

As contribuições dos resultados gerais desta pesquisa desta pesquisa, da qual este artigo se desdobra, para o campo das Ciências da Comunicação se estabelecem na esfera da ordem científica teórica, pois as articulações de seus pressupostos teóricos e metodológicos objetivaram como foco principal, como já exposto, a produção de uma Grounded Theory sobre as experiências de interação de mulheres brasileiras com a publicidade contraintuitiva e as suas repercussões em estereótipos tradicionais associados à mulher negra brasileira, ofertando ao campo uma pesquisa inovadora sobre as manifestações de sentido da publicidade nos espaços da recepção.

Enfim, tais resultados também poderão servir como referência para orientar e instrumentalizar outros estudos no campo da Comunicação brasileira. Pode ainda se manifestar na ordem social e na dinâmica mercadológica do fazer publicitário, pois o conhecimento a ser produzido com base nas vozes e experiências das mulheres brasileiras permite criar alternativas que estimulem novos pensamentos, debates e outras considerações criativas e socialmente responsáveis acerca da temática em relevo. Com isso, torna-se possível promover de algum modo uma intervenção nas reflexões sobre a realidade social contemporânea e acerca do entendimento dos impactos operados pelos produtos midiáticos nas identidades. 


\section{BIBLIOGRAFIA}

- Baldin, Nelma e Munhoz, Elzira M. B. (2011): "Snowball (bola de neve): uma técnica metodológica para pesquisa em educação ambiental comunitária". Em: X Congresso Nacional de Educação - Educere. Champagnat: Curitiba, pp. 329-341.

- Bauer, Thomas A. (2010): "Media Literacy. Entrevista com Thomas A. Bauer". Em: CoMtempo. Revista Eletrônica do Programa de Pós-graduação da Faculdade Cásper Líbero, vol. 2, $\quad$ Ano $2 \quad-\quad$ dez, $\quad$ pp. $\quad 1-4 . \quad$ Disponível em: http://www.revistas.univerciencia.org/index.php/comtempo/article/viewFile/7491/6924 [26/04/2017].

- Bernardes, Dora Luisa Geraldes (2003): "Dizer "não" aos estereótipos sociais: as ironias do controlo mental”. Em: Análise Psicológica, vol. 21, n. 3, pp. 307-321.

- Bianchi, Eliane Maria Pires Giavina e Ikeda, Ana Akemi. (2008): "Usos e aplicações da grounded theory em administração". Em: Gestao.org. Revista Eletrônica de Gestão Organizacional, UFPE, vol. 6, nº. 2, p. 231-248.

- Blair, Irene V. e Banaji, Mahzarin R. (1996): "Automatic controlled processes in stereotyping priming”. Em: Journal of Personality and Social Psychology, vol. 70, nº. 6, pp. 1142-1163.

- Blair, Irene V.; Ma Jennifer E. e Lenton, Alison P. (2001): "Imagining stereotypes away: the Moderation of implicit stereotypes through mental imagery". Em: J. Pers. Soc. Psychol, vol. 81, $\mathrm{n}^{\circ} .5$, p. $828-841$.

- Blumer, Hebert (1980): “A natureza do interacionismo simbólico”. Em: David C. Mortensen (org.): Teoria da comunicação: textos básicos. São Paulo: Mosaico, pp. 119-138.

- Boyer, Pascal (2001): Religion explained: the evolutionary origins of religious thought. NY: Basic Books.

- Braga, José L. (2015): "Lógicas da mídia, lógicas da midiatização?”. Em: Antônio Fausto Neto et.al. Relatos de investigaciones sobre mediatizaciones. 1a ed. Rosario: UNR Editora. Editorial de la Universidad Nacional de Rosario, pp. 15-32.

. (2012): "Uma teoria tentativa”. Em: Revista E-compós, Brasília, vol.15, nº 3, set./dez, pp.

1-17. Disponível em: http://www.compos.org.br/seer/index.php/ecompos/article/viewFile/811/629 [26/04/2017].

_. (2008): Comunicação, disciplina indiciária. Em: Matrizes, São Paulo, vol. 1, nº. 2, pp. 7388.

(2006): A Sociedade Enfrenta sua Mídia. Dispositivos sociais de crítica midiática. São Paulo: Paulus.

- Byrne, Sahara e Hart, Philip Solomon (2009): "The boomerang Effect: a synthesis of findings and a preliminar theoretical framework". Em: Communication Yearbook. vol. 33, nº. 1, pp. 3-37.

- Charmaz, Kathy (2009): A construção da teoria fundamentada: guia prático para análise qualitativa. Trad. de Joice Elias Costa. Porto Alegre: Artmed. 
- Dasgupta, Nilanjana y Greenwald, Anthony G. (2001): "On the Malleability of Automatic Attitudes: Combating Automatic Prejudice With Images of Admired and Disliked Individuals". Em: Journal of Personality and Social Psychology, vol. 81. nº. 5. pp. 800-814.

- Di Nallo, Egeria (1999): Meeting points. Soluções de Marketing para uma sociedade complexa. São Paulo: Ed. Cobra.

- Elias, Norbert (1978): What is Sociology? London: Hutchinson.

- França, Vera V. (2008): "Interações Comunicativas: a matriz conceitual de G. H. MEAD”. Em: Alex Primo et. al. Comunicação e Interações. Livro da Compós. Porto Alegre: Sulina, pp. 71-91.

. (2007): "Contribuições de G. H. Mead para pensar a comunicação". Em: Anais do XVI

Encontro Anual da Compós. Curitiba: UTP. Disponível em: http://www.compos.org.br/data/biblioteca_219.pdf [26/04/2017].

- Fry, Peter (2002): "Estética e política: relações entre "raça", publicidade e produção da beleza no Brasil". Em: Goldenberg, Miriam (org.): Nu \& Vestido: dez antropólogos revelam a cultura do corpo carioca. Rio de Janeiro: Record, pp. 303-326.

- Glaser, Barney e Strauss, Anselm (1967): The discovery of grounded theory: strategies for qualitative research. Chicago/NY: Aldine de Gruyter.

- Hepp, Andreas e Hasebrink, Uwe (2013): "Human interaction and communicative figurations. The transformation of mediatized cultures and societies". En: Communicative Figurations. Working Paper, $n^{\circ}$. 2, pp. 3-22.

- Hepp, Andreas (2014) “As configurações comunicativas de mundos midiatizados: pesquisa da midiatização na era da "mediação de tudo"”. Em: Matrizes, vol. 8, no. 1, jan./jun., pp. 45-64. (2012): "Mediatization and the 'molding force' of the media". Em: Communications, $\mathrm{n}^{\circ}$. 37, pp. 1-28.

- Heep, Andreas e Krotz, Friedrich (2014): "Mediatized worlds: Understanding everyday mediatization". Em: Andreas Hepp e Friedrich Krotz (eds.): Mediatized worlds: Culture and society in a media age. London: Palgrave, p. 1-15.

- Hohlfeldt, Antônio (2001): “As origens antigas: a comunicação e as civilizações”. Em: Antônio Hohlfeldt; Luiz Martino e Vera França (orgs): Teorias da comunicação: escolas, conceitos, tendências. Petrópolis: Vozes, pp. 61-98.

- Hutchinson, Sally A. (1998): "Education and grounded theory". Em: Robert R. Sherman e Rodman D. Webb: Qualitative research in education: focus and method. Londres: Falmer Press, pp. 123-140.

- Krotz, Friedrich (2014): "Media, Mediatization and Mediatized Worlds: a discussion of the basic concepts". Em: Andreas Hepp e Friedrich Krotz (eds.): Mediatized worlds: Culture and society in a media age. London: Palgrave, pp.72-87.

- Krüger, Helmuth (2004): “Cognição, estereótipos e preconceitos sociais”. Em: Marcus Eugênio Oliveira Lima: Estereótipos, preconceitos e discriminação: perspectivas teóricas e metodológicas. Salvador: EDUFBA, pp. 23-40. 
- Leite, Francisco (2015): "Experiências de interação de mulheres brasileiras com publicidade contraintuitiva: Um estudo em Grounded Theory”. Tese Doutoral - Departamento de Relações Públicas, Propaganda e Turismo/ Escola de Comunicações e Artes/ USP. São Paulo. (2014): Publicidade Contraintuitiva: Inovação no Uso de Estereótipos na Comunicação. Curitiba: Editora Appris. (2009): "A propaganda contraintuitiva e seus efeitos em crenças e estereotipos". Dissertação (Mestrado) - Departamento CRP/ ECA/ USP. São Paulo.

- Leite, Francisco e Batista, Leandro. L. (2008): “A publicidade contraintuitiva e o efeito ricochete". Em: Revista Galáxia, nº. 15, pp. 155-166.

- Luckmann, Benita (1970): “The small life-worlds of modern man”. Em: Social Research, vol. $37, n^{\circ} .4$, pp. $580-596$.

- Martín-Barbero, Jesús (1987): De los medios a las mediaciones. Barcelona: Gustavo Gili.

- Mead, George Herbert (1982): Espiritu, persona y sociedad: desde el punto de vista del condutismo social. Barcelona: Paidos. (Trabalho original publicado em 1934).

- Nunes, Jordão H. (2005): O interacionismo simbólico e a dramaturgia: a sociologia de Goffman. São Paulo: Humanitas/Goiânia: Editora da UFG.

- Osorio, Rafael Guerreiro (2013): “A classificação de cor ou raça do IBGE revisitada". Em: José Luis Petruccelli e Ana Lucia Saboia (orgs.): Estudos e Análises. Informação Demográfica e Socioeconômica. Características Étnico-Raciais da População: Classificações e Identidades. Rio de Janeiro: IBGE, pp. 83-99.

- Piedras, Eliza R. (2009): Fluxos Publicitários: anúncios, produtores e receptores. Porto Alegre: Sulinas.

- Santos, Walberto Silva dos et al. (2006): "Escala de racismo moderno: adaptação ao contexto brasileiro". Em: Psicol. Estud., vol. 11, n. 3, set./dez, pp. 637-645.

- Shibutani, Tamotsu (1955): "Reference groups as perspectives". Em: American Journal of Sociology, vol. 60, nº. 6, pp. 562-569.

- Strauss, Anselm L. e Corbin, Juliet (2008): Pesquisa qualitativa: técnicas e procedimentos para o desenvolvimento de teoria fundamentada. Trad. de Luciane de Oliveira da Rocha. $2^{\mathrm{a}} \mathrm{ed}$. Porto Alegre: Artmed.

- Tarozzi, Massimiliano (2011): O que é grounded theory? Metodologia de pesquisa e de teoria fundamentada nos dados. Trad. de Carmen Lussi. Petrópolis, RJ: Vozes.

- Trindade, Eneus (2008): “Recepção e práticas de consumo”. Em: Revista Fronteiras, São Leopoldo, vol. 31, no. 2, pp. 73-80.

- Upal, M. Afzal (2007): "What is More Memorable Counterintuitive Concepts Interpreted Metaphorically or Literally?”. Em: The 29th Annual Meeting of the Cognitive Science Society, pp. 1581-1586.

(2009): “An Alternative Account of the Minimal Counterintuitiveness Effect". Em: Cognitive Systems Research, vol. 11, pp. 194-203.

- Wegner, Daniel M. (1994): “Ironic processes of mental control”. Em: Psychological Review, vol. 101, no. 1, pp. 34-52. 